\title{
Retroactive Interference: Forgetting as an Interruption of Memory Consolidation
}

\author{
Marcus Vinicius Costa Alves ${ }^{1}$ \\ Departamento de Psicobiologia, Universidade Federal de São Paulo, São Paulo, SP, Brazil \\ Orlando Francisco Amodeo Bueno \\ Departamento de Psicobiologia, Universidade Federal de São Paulo, São Paulo, SP, Brazil
}

\begin{abstract}
Although experimenting with forgetting is complex, forgetting is not only a condition experienced by individuals every day but also an extremely important concept in memory science. Some theories that attempt to define the science of forgetting are presented in this study; however, we have focused here on the theory of interference, retroactive interference (RI) in particular. RI is the interference that occurs when a task or piece of information is inserted between the presentation of target information and its subsequent recall. Although RI can be explained as competition between items, some have now proposed that it results from the interruption of the process of memory consolidation, through which information become stable; neural processes following the initial recording of information contribute to the definitive — or, at least, longer lasting - record of this information. RI disrupts post-learning processes, resulting in the loss of these materials. This study proposes a deeper investigation of RI and memory consolidation to obtain a better understanding of this important concept, seeking to deepen knowledge of this hypothesis and other possible causes of forgetting.
\end{abstract}

Keywords: Forgetting, long-term memory, interference theory, memory consolidation.

\section{Interferência Retroativa: O Esquecimento como uma Interrupção na Consolidação da Memória}

\section{Resumo}

O esquecimento é uma condição vivenciada diariamente pelos indivíduos e um conceito de extrema importância para a ciência da memória, apesar de sua experimentação ser complexa. Algumas teorias que tentam definir a ciência do esquecimento são apresentadas neste estudo, todavia, aqui focamos na Teoria da Interferência, principalmente na Interferência Retroativa (IR). A IR é a interferência que ocorre quando uma informação ou tarefa é inserida entre a apresentação de uma informação-alvo e sua posterior recordação. A IR pode ser explicada como uma competição de itens, mas atualmente surge a proposta que ela seja fruto da interrupção de um outro processo, chamado de Consolidação da Memória. A consolidação da memória é o processo através do qual as informações tornam-se estáveis, a partir de processos neurais posteriores ao registro inicial de uma informação que contribuem para o registro definitivo - ou, ao menos, mais duradouro - desta informação. A IR perturbaria estes processos posteriores à aprendizagem, resultando na perda destes materiais. O presente estudo visa propor a possibilidade

Mailing address: Rua Botucatu, 862, Vila Clementino. São Paulo, SP, Brazil 04023062. Phone: (11) 21490155. E-mail: costaalves.mv@gmail.com.

Acknowledgements: The authors would like to thank the institutions Fundação de Amparo à Pesquisa do Estado de São Paulo (FAPESP), Coordenação de Aperfeiçoamento de Pessoal do Nível Superior (CAPES) and Associação Fundo de Incentivo à Pesquisa (AFIP), which made this study possible.. 
da investigação mais aprofundada deste tópico para a melhor compreensão desse relevante conceito, visando aprofundar o conhecimento desta hipótese e outras possíveis causas do esquecimento.

Palavras-chave: Esquecimento, memória de longo prazo, Teoria da Interferência, consolidação da memória.

\section{Interferencia Retroactiva: Olvido como una Interrupción en la Consolidación de la Memoria}

\section{Resumen}

El olvido es una condición experimentada diariamente por individuos y un concepto de suma importancia para la ciencia de la memoria. En el presente estudio algunas teorías que tratan de definir la ciencia de olvido serán discutidas y aquí nos centramos en la teoría de la interferencia, especialmente en la interferencia retroactiva (IR). El IR es la interferencia que se produce cuando se introduce una información o tarea entre la presentación de una información y su posterior recordación. Recientemente viene la propuesta de que la IR es el resultado de la interrupción de otro proceso, llamado consolidación de la memoria. Consolidación de la memoria es el proceso por el cual ocurre la estabilización de la información, a partir de procesos neuronales posteriores al registro inicial de información que contribuyen al registro definitivo - o por lo menos, más duraderos - de esta información. El IR podría teóricamente perturbar estos procesos posteriores al aprendizaje, lo que resulta en la pérdida de estas informaciones. El presente estudio tiene como objetivo proponer una investigación mas profunda de este tema para comprender mejor este importante concepto, dirigido a profundizar el conocimiento de esta hipótesis y de otras posibles causas del olvido.

Palabras clave: Olvido, memoria a longo plazo, Teoría de la Interferencia, consolidación.

Forgetting is no mere vis inertiæ... it is rather an active and in the strictest sense positive faculty of repression, that is responsible for the fact that what we experience and absorb [does not enter] our consciousness ... there could be no happiness, no cheerfulness, no hope, no pride, no present, without forgetfulness. (Nietzsche, 1887/1999)

Forgetting is a natural condition. An inability to recall previously learned information is probably one of the most common afflictions experienced by individuals in their daily lives, and perhaps because it is so common, it tends to be neglected as a factor of vital scientific importance. Although forgetting is usually labeled as harmful and causing exasperation, forgetting can also be considered an adaptive factor; it is a necessary process for refreshing information and subsequently adapting individual behavior to the environment, allowing other memories to eventually be recorded and selected (Roedi- ger, Weinstein, \& Agarwal, 2010; Storm, 2011). Forgetting can also play a self-protective role because the inability to forget irrelevant and useless information could make it difficult to effectively access specific and valuable information (Pergher \& Stein, 2003). Furthermore, the rare reports of individuals with a memory capacity that makes it almost impossible for them to forget reveal that the inability to forget can be as exasperating as the inability to remember (Luria, 1968; Parker, Cahill, \& McGaugh, 2006; Storm, 2011).

Although forgetting is commonly experienced by individuals in everyday life, scientifically proving the existence of a phenomenon that might be called "forgetting" is complex, demanding the attention of both psychologists and neuroscientists. Indeed, the only way to study forgetting is to measure the inability to recall previously learned information and infer the variables that create this condition. It is only possible to speculate whether information that could 
once be recalled has been completely erased and can no longer be retrieved or whether other factors are preventing the information from being retrieved (Davis, 2007).

A persistent definition of forgetting is presented by Tulving (1974): the inability to recall something in the present that could be recalled at a previous moment. Forgetting is an extremely important concept in the memory sciences because it allows a range of mnemonic processes to be shown, revealing how different types of memories are lost in different ways (McGeoch, 1932; Rubin, 2007).

Memory has a number of distinct systems that can be differentiated by observing not only the type of information processed but also the retention time and storage capacity associated with that information (Squire, 2004). Thus, if the cognitive process responsible for the retention and retrieval of information is complex, the loss of information in this process also becomes multifaceted (Tulving, 1974).

\section{Theories of Forgetting}

One of the pioneers of the study of forgetting was Ebbinghaus (Pergher \& Stein, 2003; Wixted, 2004). Analyzing information retention (i.e., word lists) over time, Ebbinghaus constructed his famous forgetting curve, in which a longer time interval between retrieving information corresponds to a steeper decline in the amount of information recalled (Roediger et al., 2010).

Ebbinghaus' experiments showed that a piece of information exponentially loses its ability to be revived over time - quickly at first and more slowly thereafter; those experiments are important for formulating hypotheses related to one of the oldest theories of forgetting: decay theory, which suggests that information loss occurs with the passage of time (Hardt, Nader, \& Nadel, 2013; Wixted, 2010).

Decay theory proposes that information is gradually erased from an individual's neural systems over time (i.e., it is gradually and inexorably lost; Roediger et al., 2010).

One way of theorizing forgetting is to consider it an absolute loss of stored information
(Davis, 2007). Therefore, forgetting is the total disappearance of memory traces - information stored and retained because of an original perception of some event - in an implicit or explicit way; there is no possibility of recalling the information, regardless of which techniques are used for the recall attempt (Davis, 2007; Tulving, 1974). Although it is difficult to prove the nonexistence of lost memory traces, the explanatory possibility that arises from this theory is strengthened by the idea that individuals cannot recall many aspects of their lives during their development, regardless of the techniques and clues used to attempt to bring these memories to the surface (Roediger et al., 2010).

Loss of information over time, although plausible, cannot be considered the only form of forgetting. First, to explain forgetting in this way is to state that memories are like muscles - atrophying when not used - and to avoid specifying a mechanism that causes this forgetting. Second, this theory cannot justify studies showing that numerous factors - not only time - can intervene in fixing memories (Lechner, Squire, \& Byrne, 1999; McGeoch, 1932; Roediger et al., 2010; Wixted, 2004).

Another theory of forgetting, retrieval theory, posits that forgetting results from the inability to retrieve information (i.e., even though information is present in individuals' brains, they cannot retrieve it; Roediger et al., 2010; Wixted, 2010). The phenomenon of forgetting is dependent on clues (i.e., it reflects the failure to retrieve an intact memory trace because of changes in individuals' cognitive context; Tulving, 1974). Essentially, this theory claims that a memory trace is not necessarily lost forever when it cannot be recalled; it might only be inaccessible (Tulving, 1974). Recognition tasks involving clues are commonly used to test this assertion because clues activate the memory trace recorded about a piece of information, facilitating its retrieval (Tulving, 1974; Wixted, 2010).

Another prominent theory in the study of forgetting and loss of information is interference theory, which claims that forgetting is caused by intervening information that interferes with tar- 
get information (Lechner et al., 1999; Wixted, 2004). Interference theory is one of the most important classical theories for understanding forgetting (McGeoch, 1932; Pergher \& Stein, 2003; Wixted, 2004). For many years, this theory was the most common paradigm used to explain forgetting, and although it has received criticism in the years following its proposal - and was even put aside for several decades - it is reemerging as one of the most efficient explanations for forgetting, based on the proposal that supervening processes to learning can influence individuals' information loss (Dewar, Cowan, \& Della Sala, 2007; Wixted, 2004).
Interference theory proposes that pieces of information compete with each other, overlapping in memory systems (Dudai, 2004; Wixted, 2004). Information competition can refer to either previously (proactive interference, PI) or subsequently (retroactive interference, RI) learned items. The classic paradigm for experiments with interference is shown as follows: when there is an A-B design, the first (A) and second item (B) compete for recall: when A interferes with $\mathrm{B}$, the interference is proactive; when $\mathrm{B}$ interferes with $\mathrm{A}$, the interference is retroactive (Figure 1).

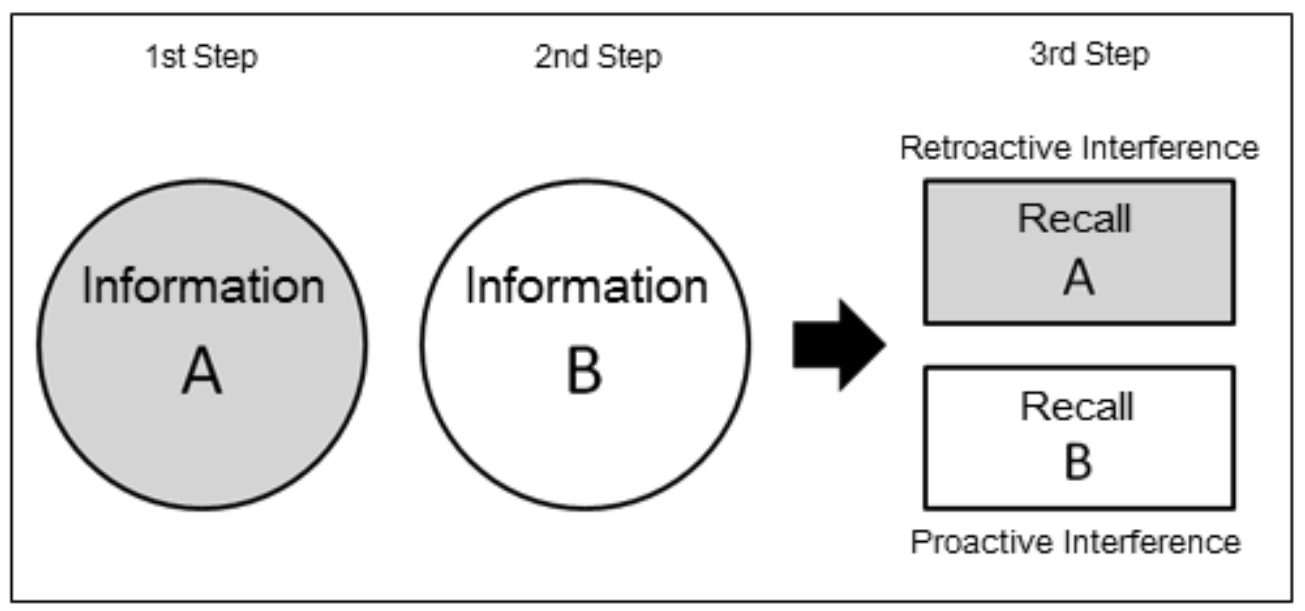

Figure 1. Classic paradigms of interference theory. Image taken from Alves (2013).

At some point, the research that sought to explain forgetting using only this theory, especially RI, declined (Anderson, 2003). One of the critical works responsible for this change is that of Underwood (1957), who suggests that most information is lost because of PI, not RI. This influential work led to a long hiatus in the research into RI's influence on forgetting and memory consolidation.

Nevertheless, the criticism posed by Underwood's study has faded over time; recent studies suggest that RI is a consistent factor in forgetting (Cowan, Beschin, \& Della Sala, 2004; Dewar, Cowan, \& Della Sala, 2007, 2010; Lechner et al., 1999; Wixted, 2004, 2010). RI again began to be used in experiments, but without neglecting PI (Wixted \& Rohrer, 1993). Thus, understanding how post-learning interferences influence infor- mation loss remains an open topic for extensive research in memory science (Wixted, 2004).

\section{The Return of Retroactive Interference as a Possible Explanation for Forgetting}

RI emerged with the works of Müller and Pilzecker in 1900 (apud Lechner et al., 1999) and was initially called retroactive inhibition (Anderson, 2003). RI was initially defined as the interference that occurs when a piece of information or a task is inserted between the presentation of target information and the subsequent recall of that information (Cowan et al., 2004; Dewar et al., 2007; Lechner et al., 1999; McGaugh, 1999).

Interference theory can be easily explained as a case of retrieval theory: interfering, proactive and retroactive tasks decrease the discrim- 
inability of items to be retrieved, generating confusion among them. Numerous researchers tend to interpret the effect of interference on the retrieval of information as derived from an inhibition process (Anderson, 2003; Anderson, Green, \& McCulloch, 2000; Anderson \& Spellman, 1995; Fawcett \& Taylor, 2008). For Anderson (2003), forgetting occurs through the control mechanisms involved in the inhibition of irrelevant information (i.e., interference is a process that arises out of mental and behavioral control systems). Consequently, forgetting does not occur through a passive process of loss but instead through an inhibitory process in which some information is more cognitively important than other information for future retrieval, thus suppressing the less relevant information (Anderson, 2003; Fawcett \& Taylor, 2008). From this perspective, the act of remembering some information - and thus making it more relevant - causes other information to be lost (Anderson, 2003; Anderson, Bjork, \& Bjork, 1994; Chan, Erdman, \& Davis, 2015). This idea raises several methodological challenges and has very interesting theoretical consequences. According to this proposal, the mere idea that interfering stimuli and traces cause forgetting is impractical, thus introducing the proposal that whether it is intentional or incidental, forgetting results from a response to the interference caused by competitors' activation in the memory.

A recent study of children and adolescents presents evidence that children experience ostensible RI effects (Darby \& Sloutsky, 2015). Darby and Sloustky (2015) show that regardless of participants' age, the PI effects are the same; for RI, the insertion of interfering stimuli is catastrophic, but only for children. This result corroborates the hypothesis that executive processes are related to RI, considering that children with lower executive development are more prone to inhibitory errors and therefore more susceptible to interference.

Another factor indicating the possibility that retrieval competition is the most important factor in RI is that competition between intervening stimuli is also dependent on individuals' attentional resources, which sort out what to keep and what not to keep when all information has previously been recalled. Thus, with the maturation of the cognitive system, individuals become less susceptible to RI effects (LewisPeacock \& Norman, 2014).

Criticism of Retroactive Interference Theo$r y$. Despite the fact that RI has regained stronger scientific value and recently been observed with great interest, it should be remembered that powerful arguments against the generalist gaze of interferences were raised some time ago. In his review, previously cited in this study, Underwood (1957) precisely addresses the generalist characteristic of the argument proposed in interference theory. Underwood's classic review points not to the nonexistence of interference as an explanation for forgetting but instead (and primarily) to the excessive use of this theory to explain, for example, the decrease in individuals' recall 24 hours after the experiment. Numerous studies have reported various results for recall after that period; all of them ascribed this loss to the different RI to which people are susceptible during the day but do not provide a thorough explanation of this phenomenon. One generalist explanation is that individuals probably lose the information acquired during the experiment because that information competes with daily information acquired post-laboratory.

What Underwood (1957) demonstrates is that this effect came primarily from the amount of prior information - word lists - presented to the individual, giving them the tendency to avoid fixing a large amount of information during the experiment (i.e., for him, the individuals' loss of information is related to PI, relegating a small part of forgetting to RI). Furthermore, in this same work, there is an argument that the main interfering effect is primarily caused by the similarity of items, not competition with information from the individual's daily life.

The problem raised by this proposal arises out of data found in experiments with RI and sleep: different studies show that a period of sleep after information acquisition tends to prevent information loss (Ekstrand, 1967; Jenkins \& Dallenbach, 1927; i.e., sleep reduces RI, preventing information competition). 
Despite studies in the field of interference theory that indicate attentional and executive influence on forgetting, another explanation that is currently fashionable comes from the theory of memory consolidation.

Retroactive Interference in Memory Consolidation. The existence of RI can also be explained by a hypothetical process known as memory consolidation, which was suggested for the first time in the seminal work of Müller and Pilzecker (1900; Lechner et al., 1999; McGaugh, 1999, 2000). Consolidation theory dismisses retrieval theory as the major factor causing forgetting; according to the former, memory is not lost through competition between relevant information during retrieval.

Memory consolidation is the process through which information becomes stable over time (Dudai, 2012; Nadel \& Bohbot, 2001). Neural processes following the initial recording of information contribute to a longer-lasting record of this information, strengthening memory traces (McGaugh, 2000; Nadel \& Bohbot, 2001; Nadel \& Moscovitch, 1997). Consolidation thus refers to the gradual stabilization of a piece of information after its acquisition; therefore, a new memory needs time to stabilize (Dudai, 2004, 2012).

The memory consolidation process tends to be understood at two levels: a cellular/synaptic level and a systems level. At the synaptic level, consolidation represents the stabilization of information after its encoding in long-term memory, in specific synaptic and cellular nodes in the neural circuit that encode memory, which can be considered part of systemic consolidation (Dudai, 2012; Dudai, Karni, \& Born, 2015; Izquierdo \& Medina, 1997). In this review, we will focus on memory consolidation in systems (i.e., the reorganization of information after its encoding in representations distributed in longterm memory neural circuits; Dudai et al., 2015).

During consolidation, when critical processes for fixing memories occur, information is susceptible to amnesic agents, such as interfering information, tasks that require cognitive effort, electroconvulsive shocks, toxins, certain drugs, brain lesions, transcranial magnetic stimulation, etc. RI disrupts the processes that occur after learning, resulting in the loss of information (Dewar, Cowan, et al., 2010; Robertson, 2012). Thus, RI occurs not only with the acquisition of new competing memories but also with any post-learning stimulus that has the ability to disrupt or deregulate the consolidation process (Figure 2; Dewar et al., 2007; Dudai, 2004; McGaugh, 1966, 2000; Robertson, 2012; Squire \& Alvarez, 1995). After some time, however, these disruptive situations lose their ability to negatively influence memory. The memory in question can finally be considered consolidated (i.e., unlikely to be susceptible to disruptions; Dudai, 2004; McGaugh, 1966; Wixted, 2004). The permanent consolidation of a memory could indicate that this information is no longer susceptible to any factor that could have previously disrupted it. However, this view has been challenged by recent studies suggesting that the reactivation of once - consolidated information tends to cause these memories to become labile (i.e., they are once again susceptible to changes and subject to transformations and adaptations, a process called memory reconsolidation; Dudai, 2004, 2012; Dudai et al., 2015; Gisquet-Verrier et al., 2015).

There is no consensus among scientists regarding the time required for consolidation to be affected; there is evidence that consolidation might take place over an extremely variable period of time and that subsequent stages, in which the reorganization of neuronal processes occur, can last from a few minutes to a few years (Dudai, 2004; Lechner et al., 1999; McGaugh, 2000). Consolidation theory reflects the idea of an irretrievable loss of information because information that has not been consolidated cannot be recovered. It is clear that the concept of memory consolidation resembles the concept of RI; ever since the seminal works on this topic, fundamental discoveries about the consolidation process show that interruptions interfere with it (McGaugh, 2000). What has changed is the idea that interfering agents are not intrinsically related to the material to be remembered. 


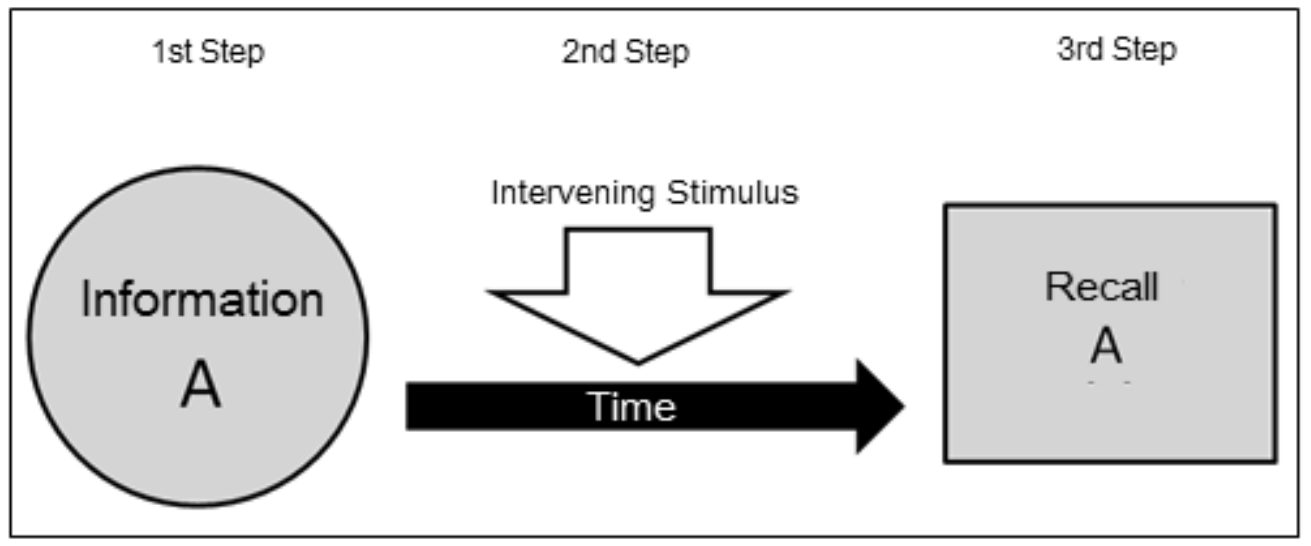

Figure 2. Retroactive interference during memory consolidation. Image taken from Alves (2013).

Structurally, the medial temporal lobe - or, more specifically, the hippocampal formation (which is commonly referenced as consisting of the hippocampus, dentate gyrus, subiculum and entorhinal cortex (Wixted, 2004)) - seems to have an important relationship with memory consolidation; if this formation suffers damage before the consolidation process is complete, memories that have not yet been consolidated are unable to be recalled (Lechner et al., 1999; Nadel \& Moscovitch, 1997; Wixted, 2004). The permanent registration of memories would occur through their gradual storage - previously dependent on the hippocampal system - in the neocortex, based on the reorganization of the neural circuitry after the information has been encoded through the constant perseverance of the information learned, which becomes independent of the hippocampus (Dudai, 2012; Lechner et al., 1999; McGaugh, 1999; Squire \& Alvarez, 1995; Wixted, 2010). Although researchers usually attribute the inhibitory mechanisms of cognition related to the prefrontal cortex - to the existence of RI (Anderson, 2003; Anderson et al., 2000; Anderson \& Spellman, 1995), there is also a hypothesis that the hippocampal formation - which is important for consolidation - is related to the loss of information in RI because, according to some researchers' interpretation, the hippocampus is fundamental to reducing susceptibility to interference (Andrejkovicks, Balla, \& Bereczki, 2013; Winocur, Becker, Luu, Rosenzweig, \& Wojtowicz, 2012; Wixted, 2004).
To understand this progressive stabilization of information, studies with amnesic patients seem to provide a good indication of the existence of both the consolidation process and the structures that permeate this process (Cowan et al., 2004; Dewar et al., 2007; Dudai, 2004, 2012). Patients who have suffered injuries to the medial temporal lobe and present anterograde amnesia (i.e., the inability to retain new events, despite the ability to hold on to new memories for a short span of time) may also present a slight retrograde amnesia (i.e., the loss of a certain amount of information before the amnesiacausing event; Squire \& Alvarez, 1995). This small loss may indicate that these materials have not yet been consolidated (Dudai, 2012; Lechner et al., 1999; Squire \& Alvarez, 1995). However, what best characterizes the effect of injuries to the medial temporal lobe is anterograde amnesia of long-term memories, which suggests that processes after information receipt are necessary for memories to be fixed in the brain, a process that loses its feasibility in these patients because of the causative factor of amnesia (Dewar, Della Sala, Beschin, \& Cowan, 2010; Nadel \& Bohbot, 2001; Nadel \& Moscovitch, 1997).

Recent studies using word lists with patients suffering from anterograde amnesia reveal that when information is presented for later recall and followed by an interval in which no task is carried out, there is greater recall of the target information (Cowan et al., 2004; Dewar, Della Sala, et al., 2010). It has been argued that this ef- 
fect exists because of the characteristics of memory consolidation. One particularity of this type of condition is that patients with amnesia-related deficits have fewer resources for consolidation, thus rendering the degradation of memory traces from RI effects considerably more visible (Brown, 2002; Cowan et al., 2004; Dewar, Cowan, et al., 2010). Moreover, such results indicate that an interval in which no cognitive activity is engaged enables the neural processes that are required for consolidation to occur. Thus, the cognitive effort used in tasks that occur after learning emerges as a possible factor that has a considerable influence on memory consolidation (Cowan et al., 2004; Dewar, Cowan, et al., 2010).

Various effects can lead to an increase or decrease of RI; much of individuals' information loss is caused by non-specific conditions arising out of RI, such as the type of task performed in the interference, the context in which the tests are carried out, and the type of encoding in the memory system required for performing tasks and recalling the target information (Robertson, 2009, 2012; Unsworth, Brewer, \& Spiller, 2013; Wixted, 2004). Although the range of interference possibilities is broad (similarity, cognitive effort, amnesic agents, drugs, etc.), the results from RI studies appear to be very similar and can be interpreted as the consequences of intervening stimuli that affect the consolidation process. Two questions should be raised: how much of the memory trace had already been established when the interfering factor appeared and how does this factor affect the subsequent neural processes that are fundamental to consolidation (Dewar et al., 2007; Dewar, Garcia, Cowan, \& Della Sala, 2009; Robertson, 2012; Wixted, 2004).

The argument for the idea that RI generates forgetting becomes even more plausible when considering numerous studies suggesting that when information acquisition is followed by an interval during which no task is performed, individuals can recall information more easily (Abel \& Bäuml, 2012; Dewar et al., 2007; Dewar, Della Sala, et al., 2010; Wixted, 2010). Therefore, the most widely used paradigm to counter RI involves establishing an interval during which participants do not perform any task and are instructed to suppress any echo (whether vocal or subvocal) of the previously presented information (Dewar et al., 2007; Wixted, 2004).

Criticism of the Theory of Memory Consolidation. One of the challenges to the theory of memory consolidation is, for example, that of Muller and Pilzecker, who theorize that consolidation would last for short periods of time: less than ten minutes (Lechner et al., 1999). However, this fact has not been found in human studies, given that consolidation can take a few minutes to a few hours or more (Brown, 2002). The time required for a memory to be consolidated is still a matter of debate; although we can understand that some information is labile for an extended period of time - and may be damaged - it is also clear to cognitive psychologists that it is possible to retain (in the short term) information almost immediately (McGaugh, 2000). One possible explanation for this phenomenon is that the memory consolidation process is not only punctual but also occurs from the beginning of the memory's acquisition: its slow duration arises out of an adaptive function that enables endogenous processes activated by experience to modulate the strength of memory (McGaugh, 2000); some memories thus become more stable than others.

Consolidation is rarely used for theoretical explanations among psychologists and neuroscientists working with humans because of the difficulty of testing it diligently in humans; in animals, the theory is extremely well established (McGaugh, 2000). The data referring to the study and models of forgetting have taken a different form in studies with a behavioral bias, in which the term "memory consolidation" is rarely addressed. In contrast, studies in nonhumans address consolidation extensively. Considering this point, it might be possible to speak about forgetting without referring to the memory consolidation process and thus merely to address the behavioral content of that process. Despite criticism, however, consolidation theory is important for explaining the processes that occur after information acquisition, remembering that 
studies in nonhuman animals have already effectively demonstrated that this process occurs.

\section{Conclusion}

Recent studies have not only shown the feasibility of returning to interference theory as a plausible proposal for forgetting but also related this theory to memory consolidation, enlarging the investigative scope that connects studies in humans and nonhumans, thus establishing a more prominent relationship as the subject of scientific research. Although both theories have been criticized, the model has been diligently used in recent years to explain the phenomenon of forgetting in an attempt to reconcile research on healthy animals and humans with research on animals and humans with some cognitive impairment. Given that consolidation decreases the fragility of memory traces, theories and studies related to memory should address consolidation as an influential phenomenon in this process (Brown, 2002). From a neurophysiological perspective, forgetting eventually mobilizes physiological mechanisms that mediate time-dependent forgetting (Dong et al., 2016; Sachser et al., 2016; Villareal, Do, Haddad, \& Derrick, 2002). According to these recent findings, memory can last indefinitely, provided it is protected from the active forgetting associated with specific neurochemical mechanisms. This possibility opens up a completely new and unexpected treatment perspective for pathological memory disorders.

This study thus proposes carrying out more experimental studies to better scrutinize this topic; such studies should be conducted strictly for the sake of investigating the fundamental causes of forgetting. More clinical studies are also necessary, particularly with patients who have either amnesia or memory deficits that render them more susceptible to multiple interferences, thus enabling an analysis of how that factor relates to healthy volunteers. Furthermore, it is important that the studies move beyond the classical forms of research into interference, leaving classic word pairs behind and investigating other potentially intervening variables, such as the cognitive effort involved in interfering tasks, attentional and executive demands, short-term memory demands and the time taken for tasks to become more or less interfering.

The study of forgetting is important for the science of memory because this topic allows us to raise questions and find fruitful answers for understanding memory itself. The ability to remember is key to survival; after all, remembering something allows individuals both to predict what will happen in the future and to adapt their behavior accordingly. Although the concept of forgetting is both widely experienced and present in individuals' daily lives, there is no consensus about its scientific and methodological definition. However, the existence of forgetting is also the result of adaptive questions. In the end, forgetting what is irrelevant allows us to remember what is essential.

\section{References}

Abel, M., \& Bäulm, K. H. (2012). Sleep can eliminate list-method directed forgetting. Journal of Experimental Psychology: Learning, Memory, and Cognition, 22, 1-7. doi:10.1037/a0030529

Alves, M. V. C. (2013). Interferência retroativa de diferente demandas cognitivas na consolidação da memória (Master's thesis, Departamento de Psicobiologia, Universidade Federal de São Paulo, Escola Paulista de Medicina, SP, Brazil)

Anderson, M. C. (2003). Rethinking interference theory: Executive control and the mechanisms of forgetting. Journal of Memory and Language, 49, 415-445. doi:10.1016/j.jml.2003.08.006

Anderson, M. C., Bjork, R. A., \& Bjork, E. L. (1994). Remember can cause forgetting: Retrieval dynamics in Long-Term Memory. Journal of Experimental Psychology: Learning, Memory and Cognition, 20(5), 1063-1087.

Anderson, M. C., Green, C., \& McCulloch, K. C. (2000). Similarity and inhibition in Long-Term Memory: Evidence for a Two-Factor Theory. Journal of Experimental Psychology: Learning, Memory and Cognition, 26(5), 1141-1159. doi:10.1037M1278-7393.26.5.I141 
Anderson, M. C., \& Spellman, B. A. (1995). On the status of inhibitory mechanisms in cognition: Memory retrieval as a model case. Psychological Review, 102(1), 68-100.

Andrejkovicks, M., Balla, P., \& Bereczki, D. (2013). Susceptibility to interference and intrusion errors in consequence of the dominant hemisphere's hipocampal infarct: A case report. Neurocase, 20(2). doi:10.1080/13554794.2012.741256

Brown, A. (2002). Consolidation theory and retrograde amnesia in humans. Psychonomic Bulletin \& Review, 9(3), 403-425. doi:http://dx.doi. org/10.3758/BF03196300

Chan, J. C. K., Erdman, M. R., \& Davis, S. D. (2015). Retrieval induces forgetting, but only when nontested items compete for retrieval: Implication for interference, inhibition, and context reinstatement. Journal of Experimental Psychology: Learning, Memory, and Cognition. doi:http:// dx.doi.org/10.1037/xlm0000101

Cowan, N., Beschin, N., \& Della Sala, S. (2004). Verbal recall in amnesiacs under conditions of diminished retroactive interference. Brain, 127, 825-834. doi:10.1093/brain/awh107

Darby, K. P., \& Sloutsky, V. M. (2015). The cost of learning: Interference effects in memory development. Journal of Experimental Psychology: General, 144(2), 410-431. doi:http://dx.doi. org/10.1037/xge0000051

Davis, M. (2007). Forgetting: Once again, it's all about representations. In H. L. Roediger III, Y. Dudai, \& S. M. Fitzpatrick (Eds.), Science of Memory (pp. 317-319). New York: Oxford University Press.

Dewar, M. T., Cowan, N., \& Della Sala, S. (2007). Forgetting due to retroactive interference: A fusion of early insights into everyday forgetting and recent research on anterograde amnesia from Müller and Pilzecker's (1900). Cortex, 43(5), 616-634.

Dewar, M. T., Cowan, N., \& Della Sala, S. (2010). Forgetting due to retroactive interference in amnesia: Findings and implications. In S. Della Sala (Ed.), Forgetting (pp. 185-209). New York: Psychology Press.

Dewar, M. T., Della Sala, S., Beschin, N., \& Cowan, N. (2010). Profound retroactive interference in anterograde amnesia: What Interferes? Neuropsychology, 24(3), 357-367. doi:10.1037/ a0018207
Dewar, M. T., Garcia, Y. F., Cowan, N., \& Della Sala, S. (2009). Delaying interference enhances memory consolidation in amnesic patients. Neuropsychology, 23(5), 627-634. doi:10.1037/ a0015568

Dong, Z., Han, H., Li, H., Bai, Y., Wang, W., Tu, M., Peng, Y., ...Wang, Y. T. (2016). Long-term potentiation decay and memory loss are mediated by AMPAR endocytosis. Journal of Clinical Investigation, 125(1), 234-247. doi:10.1172/ JCI77888

Dudai, Y. (2004). The Neurobiology of Consolidation, or, how stable is the engram? Annual Review of Psychology, 55, 51-86. doi:10.1146/annurev.psych.55.090902.142050

Dudai, Y. (2012). The Restless Engram: Consolidation never end. Annual Review of Neuroscience, 227-247. doi:10.1146/annurev-neuro-062111-150500

Dudai, Y., Karni, A., \& Born, J. (2015). The consolidation and transformation of memory. Neuron, 88(1), 20-32. doi:http://dx.doi.org/10.1016/j. neuron.2015.09.004

Ekstrand, B. R. (1967). Effect of sleep on memory. Journal of Experimental Psychology, 75(1), 6472. doi:http://dx.doi.org/10.1037/h0024907

Fawcett, J. M., \& Taylor, T. L. (2008). Forgetting is effortful: Evidence from reaction time probes in an item-method directed forgetting task. Memory \& Cognition, 36(6), 1168-1181. doi:10.3758/ MC.36.6.1168

Gisquet-Verrier, P., Lynch, L. F., III, Cutolo, P., Toledano, D., Ulmen, A., Jasnow, A. M., \& Riccio, D. C. (2015). Integration of new information with active memory accounts for retrograde amnesia: A challenge to the consolidation/reconsolidation hypothesis? The Journal of Neuroscience, 35(33), 11623-11633. doi:10.1523/ JNEUROSCI.1386-15.2015

Hardt, O., Nader, K., \& Nadel, L. (2013). Decay happens: The role of active forgetting in memory. Trends in Cognitive Sciences, 17(3), 111-120. doi:http://dx.doi.org/10.1016/j.tics.2013.01.001

Jenkins, J. G., \& Dallenbach, K. M. (1927). The effect of serial position upon recall. The American Journal of Psychology, 38, 285-291. doi:http:// dx.doi.org/10.2307/1415207

Izquierdo, I., \& Medina, J. H. (1997). Memory formation: The sequence of biochemical events in 
the hippocampus and its connection to activity in other brain structures. Neurobiology of Learning and Memory, 68, 285-316.

Lechner, H. A., Squire, L. R., \& Byrne, J. A. (1999). 100 Years of Consolidation-- Remembering Müller and Pilzecker. Learning \& Memory, 6, 77-87. doi:10.1101/lm.6.2.77

Lewis-Peacock, J. A., \& Norman, K. A. (2014). Competition between items in working memory leads to forgetting. Nature Communications, 5, 1-10. doi:10.1038/ncomms6768

Luria, A. R. (1968). The Mind of a Mnemonist: A little book about a Vast Mind. New York: Basic Books.

McGaugh, J. L. (1966). Time-dependent process in memory storage. Science, 153, 1351-1358.

McGaugh, J. L. (1999). The perseveration-consolidation hyphothesis: Mueller and Pilzecker, 1900. Brain Research Bulletin, 50, 445-446.

McGaugh, J. L. (2000). Memory: A Century of Consolidation. Science, 287, 248-251. doi:10.1126/ science.287.5451.248

McGeoch, J. A. (1932). Forgetting and the law of disuse. Psychological Review, 39, 352-370. doi:http://dx.doi.org/10.1037/h0069819

Nadel, L., \& Bohbot, V. (2001). Consolidation of memory. Hippocampus, 11, 56-60. doi:10.1002/1098-1063(2001)11:1<56::AID$\mathrm{HIPO} 1020>3.0 . \mathrm{CO}, 2-\mathrm{O}$

Nadel, L., \& Moscovitch, M. (1997). Memory consolidation, retrograde amnesia and the hippocampal complex. Current Opinion in Neurobiology, 7, 217-227.

Nietzsche, F. (1999). Genealogia da moral (P. C. de Souza, Trans.). São Paulo, SP: Companhia das Letras. (Original work published 1887)

Parker, E. S., Cahill, L., \& McGaugh, J. L. (2006). A Case of Unusual Autobiographical Remembering. Neurocase: The Neural Basis of Cognition, 12(1), 35-49. doi:http://dx.doi. org/10.1080/13554790500473680

Pergher, G. K., \& Stein, L. M. (2003). Compreendendo o esquecimento: Teorias clássicas e seus fundamentos experimentais. Psicologia USP, 14(1), 129-155. doi:10.1590/S010365642003000100008

Robertson, E. M. (2009). From creation to consolidation: A novel framework for memory process- ing. PLoS Biology, 7(1), 11-19. doi:10.1371/ journal.pbio.1000019

Robertson, E. M. (2012). New insights of human memory, interference and consolidation. Current Biology, 22, R66-R71. doi 10.1016/j. cub.2011.11.051

Roediger, H. L., III, Weinstein, Y., \& Agarwal, P. K. (2010). Forgetting: Preliminary considerations. In S. Della Sala (Ed.), Forgetting (pp. 1-22). New York: Psychology Press.

Rubin, D. C. (2007). Forgetting: Its role in the Science of memory. In H. L. Roediger III, Y. Dudai, \& S. M. Fitzpatrick (Eds.), Science of Memory (pp. 325-328). New York: Oxford University Press.

Sachser, R. M., Santana, F., Crestani, A. P., Lunardi, P., Pedraza, L. K., Quillfeldt, J. A., Hardt, O., \& Alvares, L. O. (2016). Forgetting of long-term memory requires activation of NMDA receptors, L-type voltage-dependent $\mathrm{Ca} 2+$ channels, and calcineurin. Scientific Reports, 6, 22771. doi:10.1038/srep22771

Squire, L. R. (2004). Memory system of the brain: A brief history and current perspective. Neurobiology of Learning and Memory, 82, 171-177. doi:10.1016/j.nlm.2004.06.005

Squire, L. R., \& Alvarez, P. (1995). Retrograde amnesia and memory consolidation: A neurobiological perspective. Current Opinion in Neurobiology, 5, 169-177. doi:10.1016/09594388(95)80023-9

Storm, B. C. (2011). The benefit of forgetting in thinking and remembering. Current Directions in Psychological Science, 20(5), 291-295.

Tulving, E. (1974). Cue-dependent forgetting. American Scientist, 62(1), 74-82.

Underwood, B. J. (1957). Interference and forgetting. Psychological Review, 64(1), 49-60. doi:http:// dx.doi.org/10.1037/h0044616

Unsworth, N., Brewer, G., \& Spiller, G. J. (2013). Focusing the search: Proactive and retroactive interference and the dynamics of free recall. Journal of Experimental Psychology: Learning, Memory, and Cognition, 1-15. doi:10.1037/ a0033743

Villareal, D. M., Do, V., Haddad, E., \& Derrick, B. E. (2002). NMDA receptor antagonists sustain LTP and spatial memory: Active processes mediate LTP decay. Nature Neuroscience, 5(1), 4852. doi:10.1038/nn776 
Winocur, G., Becker, S., Luu, P., Rosenzweig, S., \& Wojtowicz, J. M. (2012). Adult hippocampal neurogenesis and memory interference. Behavioural Brain Research, 227(2), 464-469. doi:10.1016/j.bbr.2011.05.032

Wixted, J. T. (2004). The Psychology and Neuroscience of forgetting. Annual Review of Psychology, 55, 235-269. doi:10.1146/annurev. psych.55.090902.141555

Wixted, J. T. (2010). The role of retroactive interference and consolidation in everyday forgetting. In S. Della Sala (Ed.), Forgetting (pp. 285-312). New York: Psychology Press. doi:10.1037/ a0020874
Wixted, J. T., \& Rohrer, D. (1993). Proactive interference and the dynamics of free recall. Journal of Experimental Psychology: Learning, Memory, and Cognition, 19(5), 1024-1039.
Recebido: 22/01/2016

$1^{a}$ revisão: 27/03/2016

$2^{a}$ revisão: 17/05/2016

Aceite final: 18/05/2016 